\title{
Pemikiran Dakwah Bediuzzaman \\ Said Nursi
}

\author{
Edi Amin \\ UIN Syarif Hidayatullah Jakarta \\ edi.amin@uinjkt.ac.id
}

\begin{abstract}
Abstraks: Tulisan ini membuktikan bahwa pemahaman dan kepatuhan pada nilai-nilai yang terkandung dalam teks panduan, dapat memantapkan suatu gerakan tersebut dalam membangun komunitas. Komunitarianisme global menekankan pentingnya panduan moral, keterbukaan dan partisipasi masyarakat, meskipun nilai-nilai keyakinan satu umat sangat dominan. Said Nursi, mencoba mendialogkan dan menawarkan konsepsi dakwah yang bersumber dari ajaran Islam guna melawan sektarianisme, fanatisme, kediktatoran, penindasan dan menjawab problematika masyarakat modern yang kompleks. Tulisan ini menguatkan teori komunitarian dengan berbasis komunikasi yang telah dibangun oleh Andi Faisal Bakti (2004 dan 2010); Peter Mandaville (2009) tentang gerakan Islam transnasional di Asia Selatan yang bercorak filantropis dan organisasi dakwah; Metin Karabaşoğlu (2003), tentang adanya hubungan antara teks dan komunitas. Disertasi ini menolak pandangan R. J. Ravault (1992) bahwa gerakan keagamaan dan sosial yang bercorak komunitarianisme adalah sektarianisme. Sumber tulisan adalah karya Said Nursi dalam Risale-i Nur yang terbit tahun 2013, buku, jurnal, hasil simposium, hasil musyawarah, dokumentasi, dan seminar.
\end{abstract}

Kata kunci: pemikiran, dakwah, bediuzzaman said nursi.

Permalink/DOI: http://doi.org/10.15408/dakwahv22i1.12065

\section{Pendahuluan}

Tokoh ulama Bediuzzaman Said Nursi, berusaha menawarkan etika komunitarian yang bersumber dari ajaran Islam untuk menjawab problematika masyarakat modern. Modern banyak diidentikkan dengan Westernisasi, Dawam Rahardjo menyatakan, "gagasan modernisasi pada awalnya dipersepsikan sebagai westernisasi. Persepsi itu adalah proses kemasyarakatan yang berorientasi pada nilai-nilai kebudayaan Barat yang dianggap lebih maju." ${ }^{1}$

Rezim Mustafa Kemal Atatürk yang membawa semangat modernisasi pada westernisasi terjebak pada sekulerisasi yang "kebablasan". Inilah yang mendorong tokoh seperti Nursi mengobarkan spirit komunitarian yang berlandaskan ajaran agama (Islam) hingga bisa disebut sebagai komunitarian ummatic. Komunitarian ummatic mengacu pada proses kemasyarakatan yang berorientasi pada nilai-nilai Islam. Cak Nur sebagaimana diungkapkan Dawam, dengan mengutip John Gardner, seorang cendekiawan yang menjabat sebagai Menteri Kebudayaan dalam Kabinet John F. Kennedy menyatakan bahwa semua peradaban besar dunia, selalu berbasis agama. ${ }^{2}$ Dalam konteks ini, nampaknya Nursi tidak berlebihan dengan optimismenya jika masa depan adalah milik Islam.

Said Nursi (1877-1960)³ merupakan salah satu tokoh kunci bagi pengembangan spiritualitas di Turki era modern. M. Sait Özervarli menyatakan:

Said Nursi is one modern scholar deeply who engaged in the revitalization of Islamic thought in modern Ottoman/Turkish society, with perhaps a greater acquaintance with social philosophy and theology compared to others. To begin with, Nursi devoted his life to the 
restoration of religious expression in the public sphere, aiming to re-establish Islam as a live and practiced religion in an age of criticism, positivistic scientism, and radical secularism. 4

Nursi hidup dalam tiga fase penting sejarah transisi di Turki, yaitu masa penghapusan kekhalifahan Usmani 1924, kemudian digantikan rezim sekuler (1925-1950), dan pasca 1950 yang dipimpin Partai Demokrat. Tiga fase sejarah tersebut ikut melatarbelakangi kehidupan dan pemikiran Nursi yang ia bagi menjadi tiga fase pula: Said Nursi lama (the old Said Nursi) (18761925), Said Nursi Baru (the new Said Nursi) (1926-1950) dan Said Nursi ketiga (the third Said Nursi) pasca 1950 hingga 1960.5 Saat Tumbangnya partai Republik dan digantikan partai Demokrat tidak serta merta sekulerisme berhenti. Sisa rezim sekuler masih terus mengawasi dan menghantui gerakan dakwah Nur yang bertujuan mendakwahkan ajaran Risale-i Nur yang dikarang Said Nursi di Turki saat itu.

Masa-masa transisi Turki diungkapkan Saritoprak dan Griffith bahwa sejak masa reformasi Ottoman (Tanzimat), Turki diliputi masalah politik, ekonomi dan sosial-budaya. Kaum intelektual merasa trauma dengan jatuhnya peradaban Islam. Puluhan problematika intelektual dan kenegaraan dibahas berulang-ulang tanpa adanya solusi yang jelas. Selain persoalan kenegaraan, masalah keagamaan juga menjadi beban. Kehidupan sosial-keagamaan sepertinya sudah mati dan terkubur bersama jatuhnya peradaban Islam. Pembangunan demokrasi Turki berjalan di atas dasar-dasar yang masih rapuh, dengan pilihan sistem partai tunggal atau sistem multi-partai. Konflik sektarian, konflik keagamaan, krisis ekonomi, kemiskinan, dan setumpuk masalah lainnya semakin memperburuk kondisi sosial. ${ }^{6}$ Situasi ini juga masih Nursi rasakan, ketika ia datang ke Istanbul pada 1907 untuk mengusulkan proyek pendidikannya ke sultan.

Ketika dikeluarkannya maklumat perang pada tahun 1914, Said Nursi mendaftar di dinas ketentaraan sebagai mufti (petugas keagamaan) dan ikut mengangkat senjata.7 Nursi menunjukkan keberaniannya dalam setiap pertempuran yang terjadi. Sebagai da’i dan cendekiwan, ia berorasi, berdialog, menulis dan berusaha mendirikan pendidikan yang ideal sesuai dengan konteks zamannya. ${ }^{8}$ Sebagian besar karya Nursi ditulis di buih dan pengasingan selama kurang lebih dua puluh lima tahun (1925-1950). Kumpulan tulisan tersebut diberi nama Risale-i Nur yang berisi enam ribu lembar lebih karyanya. ${ }^{9}$ Risale-i Nur merupakan tafsir kontekstual al-Qur'an. Nursi menulis Risale-i Nur dan menjadikan al-Qur'an sebagai pembimbingnya, sebagaimana pernyataan Nursi:

Jangan engkau mencari sesuatu yang ada dalam tungku-tungku anggur yang lezat yang tumbuh di batang kayu yang layu. Aku seperti batang kayu yang layu itu yang ditumbuhi anggur yang lezat. Andai saja suaraku dapat menjangkau ke penjuru dunia, maka akan aku katakan dengan segala daya dan upaya, bahwa kalimat-kalimat yang indah menawan yang merupakan sesuatu yang hakiki adalah bukan dari diriku sendiri, semua itu merupakan pancaran sinar kebenaran al-Qur'an. Sungguh alangkah indahnya kebenaran-kebenaran al-Qur'an itu, akan tetapi saya tidak dapat mengungkapkannya. Sesungguhnya keindahan-keindahan al-Qur'an yang hakiki itulah yang membuat indah perumpamaan-perumpamaan saya. Dan tidaklah al-Qur'an itu memuji kalimat-kalimatku. Akan tetapi kalimat-kalimatkulah yang memuji al-Qur'an. ${ }^{10}$

Saat ini yayasan yang concern mengembangkan pemikiran Nursi di Indonesia adalah Yayasan Nur Semesta yang didirikan pada tahun 2007. Yayasan Nur Semesta memiliki beragam 
aktivitas, sebagai sentral kaderisasi anggotanya terkoordinir lewat dershane. Kegiatan rutinitas dershane adalah membaca, menelaah dan mendiskusikan dan menerjemahkan karya sang tokoh. Gerakan menyebarkan pemikiran Nursi berkembang pesat tidak hanya di Turki, namun juga telah merambah Asia dan Eropa. Di Asia, dakwah Nur juga berkembang dengan baik, seperti di Vietnam, Kamboja, Indonesia, Malaysia, Thailand, Jepang, dan juga di Filipina.

Sebagai sebuah gerakan, dakwah Nur memiliki tujuan utama dan pola-pola gerakan terstruktur. Tujuan tersebut tidak lain adalah semangat mengkontekstualisasikan ajaran al-Qur'an. Dengan harapan, kontekstualisasi tersebut akan menghasilkan umat atau komunitas yang terbaik (khair al-ummah). Konsep komunitas dalam gerakan dakwah Nur perlu mendapat perhatian sebagai sebuah konsep masyarakat Islam yang diharapkan sentiasa relevan dengan kondisi zaman. ${ }^{11}$

Konsep komunitas ${ }^{12}$ di antaranya diperkenalkan oleh sosiolog Ferdinand Tönnies (18551936). ${ }^{13}$ Tönnies membagi masyarakat dalam sistem dan budaya menjadi dua kategori yang diistilahkannya dengan Gemeinschaft dan Gesellschaft. Gemeinschaft lebih cenderung tradisional dengan ciri adanya kehendak sosial yang masih kental kerukunannya, seperti gotong royong, ikatan persaudaraan atau pertemanan yang kuat, serta masih berpegang teguh dengat adat istiadat serta agama. Bentuk Gemeinschaft terutama terdapat dalam ikatan keluarga, kelompok kekerabatan, rukun tetangga dan lain sebagainya. Sedangkan Gesellschaft terkesan lebih modern dengan adanya kehendak atau kontrak sosial yang cenderung pada nilai-nilai konfensi, adanya aturan yang mengikat, dan adanya opini publik yang berkembang. Bentuknya terdapat pada organisasi pedagang, organisasi suatu pabrik dan lainnya.

Perbedaan di antara keduannya adalah bahwa dalam Gemeinschaft individu tetap bersatu meskipun banyak faktor yang memengaruhi untuk berpecah, sedangkan dalam Gesellschaft individu pada dasarnya terpisah meskipun banyak faktor pemersatu. ${ }^{14}$ Said Nursi melihat perpecahan dalam masyarakat disebabkan beberapa faktor, seperti sikap individualisme, materialisme, serta lemahnya iman. Kelebihan konsep Gemeinschaft dan Gesellschaft, diambil dengan pendekatan integration of modernity and tradition, mengambil yang positif dari tradisi dan menerima modernitas yang mendukung kemajuan.

Usulan Said Nursi terkait pentingnya bentuk pendidikan modern, pentingnya dakwah dengan kata-kata atau sebagai jihad damai (jihad of the word/cihād-i mānevī), pentingnya persatuan dan persaudaraan, pentingnya kemandirian, pemerintahan yang bersih dan kokohnya iman, mengisyaratkan bahwa ia menghendaki bentuk komunitas yang unggul. ${ }^{15}$ Komunitas yang disandarkan pada iman dan pertanggungjawabannya dengan Tuhan. Kondisi yang mana konsep Gemeinschaft dan Gesellschaft bersinergi dan menyatu. Seperti konsep Nursi tentang penyatuan pendidikan modern Barat yang cenderung sekuler dengan tanpa menghilangkan konsep pendidikan Islam tradisional. Di Turki, para murid Nur (Tullab al-Nur) lebih banyak yang menempuh studi akademik di tingkat strata satu ataupun pascasarjana pada jurusan umum, khususnya bidang science dan teknologi. ${ }^{16}$ Dan di dershane, mereka mendapat gemblengan spiritualitas dari membaca, diskusi dan mengamalkan ajaran Said Nursi dalam karyanya Risale-i Nur.

Bangunan komunitas yang unggul didasarkan pada kestabilan keamanan, dan keamanan hanya dapat terjadi manakala penduduknya saling terjalin hubungan persaudaraan. Semangat 
persaudaraan inilah yang senantiasa Nursi sampaikan. Bahkan risalah tentang ukhuwwah dan ikhlas karangan Nursi, menjadi bacaan wajib sekali dalam seminggu di setiap dershane. Gerakan dakwah Nur menekankan pentingnya solidaritas dan ukhuwwah di antara anggotannya. Konsep solidaritas atau kohesi kelompok (asabiah) telah digulirkan Ibn Khaldun sebagai salah satu bentuk fundamental dalam membentuk kekuatan sebuah negara atau komunitas. Khaldun menegaskan bahwa gerakan keagamaan tidak akan berhasil tanpa solidaritas sosial. Khaldun juga menegaskan bahwa pemerintah yang menerapkan norma-norma ke-Tuhanan akan lebih unggul. ${ }^{17}$ Normanorma agama tersebut hendaklah bersifat inklusif, hingga dapat memberikan kontribusi sebagaimana mestinya. ${ }^{18}$

Dakwah (Islamic Communication) yang Dibangun Gerakan Dakwah Nur

Sebagai gerakan sosial Islam, dakwah Nur mengupayakan agar penerima dakwah (mad'u/receiver) dapat menyerap dan mengaplikasikan nilai-nilai ajaran Islam yang terkandung dalam kitab karangan Bediuzzaman Said Nursi Risale-i Nur. Nilai-nilai tersebut hendaklah dimaknai dengan semangat dakwah yang menghendaki keterpaduan antara hubungan horizontal dan vertikal sekaligus. Sebagaimana diungkapkan Bakti:

Komunikasi Islam tentunya bukan hanya komunikasi secara horizontal kepada sesama namun juga komunikasi yang terjadi secara vertikal antara Pencipta yaitu Allah S.W.T. dengan kita sebagai hamba-Nya. Para pemikir Muslim telah mengembangkan berbagai teori komunikasi yang menjadi komunikasi alternatif yang kemudian kita sebut sebagai komunikasi Islam yang menjunjung tinggi nilai-nilai kemanusiaan dan fitrah penciptaan manusia. ${ }^{19}$

Dalam komunikasi Islam, tabligh (information) yang disampaikan selain jelas dan positif diharapkan dapat membawa perubahan bagi penerima pesan. Lebih jauh, tabligh berfungsi sebagai transformasi sosial yang tujuannya adalah perubahan. Perubahan yang baik memerlukan pembangunan dan pembinaan yang berkesinambungan, kondisi yang kondusif serta upaya-upaya kongkrit dan inovatif dalam membangun Sumber Daya Manusia (SDM). Saat pembinaan dan pembangunan berlangsung, umat memerlukan panduan, di sinilah fungsi etika (akhla $>$ q/ ethics) memainkan peran yang penting dalam menuju masyarakat terbaik. Dalam pemikiran dakwah Said Nursi, teks panduan Risa>lah al-Nu>r dan gerakannya, dapat dilihat dari perspektif teori dakwah, yaitu: 1. Tabligh; 2. Taghyir; 3. Takwin al-ummah, al-amr bi al-ma'ruf wa al-nahy 'an almunkar; Dan al-ummah al- khairiyyah, akhlaq. Teori dakwah tersebut digunakan untuk menggali pemikiran dakwah Said Nursi. Risale-i Nur karangan Said Nursi tersebut merupakan inspirasi, acuan gerakan dan mewujud dalam perilaku para Tullab al-Nur (pembaca dan pengamal Risale-i Nur).

Diperlukan masyarakat yang baik guna membangun peradaban yang gemilang dengan berdasarkan pada nilai-nilai Islam. Selain itu dibutuhkan pula kemandirian, resepsi dan partisipasi aktif dalam menyerap, mengimplementasikan setiap proses pembangunan. Umat harus mampu dan bisa membantu diri mereka sendiri (self-help-strategy) ${ }^{20}$ tanpa kehilangan fungsi kemanusiaannya sebagai hamba. Islam selalu mendorong kemajuan pembangunan dan keterlibatan manusia dalam urusan duniawi. ${ }^{21}$ Lebih lanjut, bagaimana konstruksi pemikiran dakwah Said Nursi terkait upayanya dalam membangun komunitas yang unggul dalam perspektif teori dakwah di atas, akan diuraikan dalam tulisan selanjutnya. 


\section{Pembahasan}

\section{Konsep Murasalah sebagai bentuk tabligh}

Berawal dari kondisi masyarakat Turki yang terpuruk dan mengenaskan dalam aspek sosial dan politik pada masa pemerintahan rezim sekuler Mustafa Kemal Atatürk, turut mengusik dan mendorong keterpanggilan Said Nursi untuk memperbaiki kondisi tersebut. Spirit memperbaiki dan membina ummah terlihat dari karya Said Nursi dalam Risale-i Nur. Karena pentingnya Risale-i Nur untuk dipedomani umat, maka Nursi berusaha merintis, mengembangkan dan menggalakkan gerakan dakwah membaca Risale-i Nur melalui sistem dershane. Lebih lanjut, Nursi tidak hanya mengiginkan karyanya dibaca, namun lebih penting lagi jika dipedomani dan menjadi panduan manusia modern dalam membangun komunitas dengan semangat tabligh. ${ }^{22}$

Dalam kondisi dan situasi yang sulit, Nursi terus dimata-matai dan diintimidasi setiap saat oleh rezim Mustafa Kemal. Dalam situasi tersebut Nursi tidak pernah surut dalam dakwah. Ia terus berkarnya dan menuangkan pemikirannya. Karya dalam bentuk surat-menyurat (mura $>$ salah) atau korespondensi dengan para muridnya yang berisi pesan-pesan dakwah dituangkan dalam Risale-i Nur dengan judul al-Malahiq fi fiqh da'wah al-Nur. Pesan utama dakwah dalam murasalah tersebut adalah pentingnya iman dan al-Qur'an untuk dapat dipedomani. ${ }^{23}$ Tema dan pesan tersebut sejalan dengan Risale-i Nur.

Lebih jauh perhatian Nursi terhadap Risale-i Nur diungkapkan Adib Ibrahim bahwa Nursi merupakan seorang guru agung ketika menulis pemikiran-pemikiran atau menjelaskannya kepada orang lain di sekitarnya. Ia berguru dan duduk berhadapan laksana seorang murid di hadapan gurunya, menelaahnya berulang-ulang dan senantiasa merujuk karyanya. Dan dia selalu menghimbau para muridnya agar senantiasa berpegang teguh dan mengambil pelajaran dari Risale-i Nur. Sebaliknya ia melarang murid-muridnya melirik dan memuja pribadinya. ${ }^{24}$

Nursi menekankan pentingnya aspek peribadatan individu yang dapat berdampak pada keharmonisan hubungan sosial. Pada setiap menit, bahkan setiap waktu, ungkap Nursi, manusia membutuhkan Allah, dengannya pula ruh bisa bernafas. ${ }^{25}$ Aspek tersebut relevan dengan temuan Alexis Carrel sebagaimana dikutip Shari'ati bahwa manakala doa dan tradisi beribadah mulai merosot dan dilupakan dalam suatu masyarakat, maka bangsa dan masyarakat itu tidak akan dapat bertahan dan akan mengalami keruntuhan. ${ }^{26}$ Perhatian Nursi pada kemaslahatan umat, ia kobarkan sepanjang hayatnya, untuk menjaga keterpurukan manusia di zaman modern.

Ustad Said Nursi menekankan bahwa saat dai menyampaikan pesan dakwah dan membimbing umat, hendaklah tidak menjadikan hasil sebagai tujuan. Lebih lanjut, Nursi memberikan bimbingan:

Sebagian teman bertambah semangat dan bertambah rindu kepada Risale-i Nur saat melihat orang-orang memberikan respon kepadanya. Mereka pun begitu bersemangat. Namun, ketika orang-orang tidak meresponnya, kekuatan jiwa mereka melemah dan api kerinduan mereka padam. Hal ini tentu tidak dibenarkan. Nabi Muhammad SAW. sebagai seorang guru agung, teladan, dan pemimpin tertinggi semua manusia telang menjadikan perintah Ilahi: "kewajiban Rasul hanyalah menyampaikan secara jelas" (Q.S. An-Nur (24): 54), sebagai petunjuk dan pembimbing Nabi. Karenannya, setiap kali kaum yang lemah itu berpaling, beliau justru tambah bersemangat dalam menyampaikan risalah. Sebab, beliau yakin betul bahwa 
hidayah adalah urusan Allah, sebagaimana ayat: "Sungguh, engkau (Muhammad) tidak tidak dapat memberi petunjuk kepada orang yang engkau kasihi, tetapi Allah memberi petunjuk kepada orang yang ia Dia kehendaki” (Q.S. al-Qas\}as\} (28): 56). Oleh sebab itu, Nabi tidak ikut campur dalam urusan Allah. ${ }^{27}$

Informasi positif yang disampaikan pengirim pesan kepada penerima pesan diharapkan berdampak paralel dan simetris dengan pesan yang diinformasikan. Namun jika pengirim pesan atau pesan yang disampaikan 'meragukan,' maka penerima pesan hendaklah bersikap kritis dengan melakukan tabayyun (klarifikasi), demikian ungkap Bakti dengan mengutip ayat: "jika seorang yang fasik datang kepadamu dengan membawa suatu berita (informasi), maka telitilah kebenarannya, agar kamu tidak mencelakakan suatu kaum karena kebodohan (kecerobohan), yang akhirnya kamu menyesali perbuatanmu itu" (Q.S. Al-H\}ujura>t (49): 6). ${ }^{28}$

Ustad Nursi senantiasa mengingatkan tugas utama murid-murid Nur adalah berkhidmah (hizmet) pada al-Qur'an dan iman serta menekankan pentingnya kualitas berbanding kuantitas. Nursi menegaskan, "kita semua sangat memerhatikan isi dan cara tanpa melihat banyak dan jumlahnya." 29

\section{Ustadhiyyah al-Qur'an sebagai dasar perubahan (Taghyir)}

Taghyir yang dikehendaki Nursi adalah menjadikan Al-Quran dan Sunnah Nabi sebagai acuan etika komunitas Muslim yang tertuang dalam karnyanya Risale-i Nur. Ustadhiyyah alQur'an, yang bermakna al-Qur'an sebagai guru utama, bukan berarti tidak menggunakan sunnah Nabi Muhammad SAW. Nursi senantiasa mengajak umat untuk menjadikan al-Qura'an sebagai acuan dan guru.

Nursi menekankan aspek tauhid dan iman sebagai pondasi perubahan, kesadaran dan kebahagiaan. Nursi menghendaki perubahan kearah yang positif, masyarakat yang berkemajuan baik materi maupun spiritualitas. Nursi terus berusaha agar umat bisa bangkit dan berubah dari keterpurukan kehidupan sosial dan politik. Perubahan hanya dapat terjadi dengan sikap proaktif dari masyarakat itu sendiri. Bakti menyatakan bahwa dalam perspektif komunikasi Islam, situasi dan kondisi model transisi disebut taghyir (change). Lebih lanjut Bakti mengutip al-Quran, "Sesungguhnya Allah tidak mengubah keadaan suatu kaum sebelum mereka mengubah keadaan diri mereka sendiri" (Q.S. al-Ra'd (13): 11). Tumbuhnya semangat perubahan, diharapkan dapat memperbaiki kondisi yang terjadi, dapat menghasilkan temuan-temuan dan inovasi dalam berbagai bidang, khususnya ilmu pengetahuan dan teknologi. Oleh sebab itu, para pelajar hendaklah fokus dan terus semangat berinovasi guna menghasilkan temuan-temuan baru nantinya. ${ }^{30}$

\section{Al-Shahs al-ma'nawi}

sebagai bentuk Takwin al-Ummah dan al-amr bi al-ma'ruf wa al-nahy 'an al-munkar

Takwin al-ummah dan al-amr bi al-ma'ruf wa al-nahy 'an al-munkar'31 yang disejajarkan dengan development atau pembangunan, dalam dakwah Nur merupakan upaya dalam membangun komunitas unggul yang berkemajuan dengan upaya transformasi teks Risale-i Nur ke konteks (realitas sosial). Transformasi tersebut membutuhkan energi dan spirit yang dikenal dengan dakwah sebagai bentuk tanggung jawab individu dan kelompok. Upaya ustad Nursi 
membentuk kelompok (jama'ah) atau komunitas adalah usaha kongkrit dalam upayanya membangun dan membina umat agar tidak tergerus dengan kondisi zaman dengan berpegang teguh pada nilai-nilai ajaran Islam. ${ }^{22}$

Jama'ah yang Nursi tekankan adalah komunitas yang memiliki kepribadian kolektif maknawi (al-shahs al-mánawi ) yang diikat oleh iman, ikhlas dan persaudaraan, serta nilai-nilai spirit Islam lainnya. Peluang dalam menyebarkan Risale-i Nur selalu dilakukan oleh para Tullab al-Nur sebagai upaya transformasi membangun jama'ah yang bertujuan untuk pembinaan dan perubahan menuju masyarakat yang baik. Transformasi tersebut di antarannya merubah sistem "Ana” menjadi "Nahnu,". Nursi Menyatakan:

Sesungguhnya jaman sekarang adalah---bagi Ahli hakikat--- adalah jaman berjama'ah dan bukan jaman sosok pribadi fardy (individu) serta bukan waktunya untuk memperlihatkan keegoan dan kesombongan. Maka ketahuilah bahwa sosok maknawi/kepribadian kolektif maknawi (alshahs al-ma'nawi) yang lahir dari jamaah, itulah yang menguasai dan bertahan menghadapi angin taupan (sekarang hingga masa yang akan datang). 33

Pembangunan yang hendak dicapai dalam dakwah Nur adalah kesadaran umat atas perintah Allah melalui Rasulnya. Kebahagiaan hanya dapat diperoleh melalui kesadaran untuk mengikuti ajaran Islam dengan tekun dan konsisten. Upaya mengajak orang lain ke jalan Tuhan merupakan tanggung jawab seorang Muslim, Mowlana menyatakan, "Muslims have the responsibility of guiding one another, and each generation has the responsibility of guiding the next."34 Semangat tanggungjawab dakwah tersebut yang menjadi spirit murid-murid Nur untuk menyebarkan dan membina umat di berbagai Negara. Eyup Aluçluer misalnya, seorang Vakif (Wakif) yang berasal dari Turki ketika ditanya motif ke Indonesia, jawabannya adalah karena motivasi dan semangat untuk hizmet membantu Hasbi Sen dalam mengembangkan dakwah Nur di Indonesia. 35

Makna pembangunan yang seutuhnya selain tercapainya kesejahteraan fisik (materi) adalah tercapainya kebahagaiaan nonfisik (intelektual, mental, moral dan spiritual). ${ }^{6}$ Nursi menegaskan bahwa Islam memiliki potensi untuk menggapai kemajuan spiritual dan materiil. Nursi optimis bahwa masa depan Islam secara fisik (materiil) akan memimpin. "Sebab, di jantung sosok maknawi dunia Islam terdapat lima kekuatan yang tidak bisa dikalahkan. Ia begitu kuat dan kokoh.” Lebih lanjut Nursi mengungkapkan lima kekuatan yang dimaksud:

Pertama, "hakikat Islam" yang merupakan guru bagi seluruh kesempurnaan dan kemuliaan---di mana ia menjadikan 350 juta muslim (sekarang 1,5 milyar) laksana satu jiwa, serta menyiapkan sebuah peradaban hakiki dan pengetahuan yang benar--- memiliki kekuatan yang tidak bisa dikalahkan oleh kekuatan manapun.

Kedua, "kebutuhan mendesak" yang merupakan guru hakiki bagi peradaban dan industri yang dilengkapi oleh berbagai sarana dan prinsip sempurna. Begitu pula "kemiskinan” yang membinasakan kita. Nah kebutuhan dan kemiskinan merupakan dua kekuatan yang tidak bisa dibungkam dan dikalahkan.

Ketiga, "kebebasan syar'i" yang mengarahkan umat manusia kepada jalan persaingan yang sehat menuju berbagai keluhuran dan tujuan mulia di mana ia menghancurkan segala bentuk tirani sekaligus menumbuhkan kesadaran mulia dalam diri manusia; kesadaran yang berhias sejumlah perasaan untuk bersaing, iri, bangkit secara utuh, cenderung pada pembaruan dan kemajuan. Kekuatan ketiga ini (kebebasan syar’i) bermakna menghias diri dengan sejumlah

\section{$144-151$}


derajat kesempurnaan dan keinginan padanya sebagai hal termulia yang paling layak dimiliki manusia.

Keempat, "heroisme Islam" yang disertai kasih sayang. Maksudnya, sikap tidak rela diri ini hina di hadapan kaum zalim dan tidak menghina pihak yang terzalimi. Dengan kata lain, tidak menyanjung para tirani serta tidak bersikap sombong terhadap kalangan miskin. Ini merupakan salah satu prinsip kebebasan syar'i yang sangat penting.

Kelima, "kemuliaan Islam" yang menyuarakan penegakan kalimat Allah. Pada masa kita sekarang, penegakan kalimat Allah bergantung pada kemajuan materiil dan masuk ke dalam arena peradaban hakiki. Tentu saja, sosok maknawi dunia Islam di masa mendatang akan memahami dan mewujudkan tuntutan iman untuk menjaga kemuliaan Islam. Sebagaimana kemajuan Islam di masa lalu adalah dengan melenyapkan sikap fanatik musuh, menghancurkan keangkuhannya, serta menangkal permusuhannya. Semua itu terwujud dengan kekuatan senjata dan pedang. Maka sekarang sebagai ganti dari senjata dan pedang, musuh akan dikalahkan dan dilumpuhkan lewat pedang maknawi dari peradaban hakiki, kemajuan materiil, kebenaran, dan hakikat. ${ }^{37}$

Nursi melanjutkan bahwa yang dimaksudnya dengan peradaban adalah berbagai sisi yang memberikan manfaat dan kebaikan bagi umat manusia, bukan berbagai dosa dan keburukannya. "Orang-orang yang bodoh, menganggap keburukan tersebut sebagai sebuah kebaikan sehingga menirunya dan merusak apa yang kita miliki," tegas Nursi. Nursi melanjutkan, "mereka menjadikan agama sebagai sogokan untuk mendapatkan dunia. Namun ternyata mereka tidak mendapatkannya dan tidak akan pernah mendapatkan apa-apa."38

Pembangunan moral umat menuju peradaban yang gemilang senantiasa menjadi fokus Nursi dalam karya-karyanya. Hal tersebut dimaksudkan untuk membentengi umat dari berbagai perubahan yang terus berjalan. Nursi juga mendorong umat untuk maju secara materiil, namun bukan menjadi materialistis. Hal tersebut nampak jelas dalam upayanya dalam mendirikan pendidikan yang berbasis ilmu pengetahuan dan sains modern, tanpa meninggalkan agama.

Kondisi umat yang pekat karena agama dijauhkan dari kehidupan masyarakat membutuhkan sosok yang berani menyuarakan pentingnya agama dalam kehidupan bermasyarakat. Nursi bangkit menyuarakan hakikat agama, seraya membangunkan masyarakat yang ikut terbuai dengan gelombang sekulerisme. Bagaimana usaha Nursi dalam membangun peradaban, Fethullah Gülen menyatakan bahwa Nursi memproklamirkan perang atas kebodohan, kemiskinan, dan perpecahan. Ia mendobrak berbagai asumsi dan ilusi yang membayangi masyarakat. Di samping memproklamirkan perang terhadap atheisme dan pengingkaran terhadap Tuhan, ia juga menenggelamkan berbagai kebatilan dan khurafat serta menutup pintu darinya. Keberanian Nursi sulit dicarikan tandingannya, ia mendiagnosa sejumlah problem dan penyakit kronis, seraya memberikan cara penyembuhan darinya. 39

Pembangunan dan pembinaan umat yang dimaksudkan Nursi adalah upayanya dalam melindungi dan menumbuhkan ketahanan masyarakat dari berbagai problematika yang muncul seiring perkembangan zaman. Spirit karyanya dalam Risale-i Nur yang menjadi panduan, mencerminkan usaha total Nursi dalam membangun peradaban masyarakat yang sesuai dengan nilai-nilai Islam. Dalam melaksanakan amar makruf nahi mungkar, ungkap Moqsith Ghazali diperlukan pula kearifan para penegak amar makruf nahi mungkar agar aktivitasnya tidak kian menambah jumlah kemungkaran di tengah masyarakat.40 


\section{Al-fana'fi al-ikhwan dalam mewujudkan khairiyyah al-ummah}

Modernitas dengan segala keunggulan dan kekurangannya memerlukan panduan agar tidak 'kebablasan.' Fazlur Rahman mengusulkan suatu etika yang bersumber dari al-Qur'an untuk memandu dan kritis terhadap modernitas. ${ }^{41}$ Nilai-nilai kebaikan dalam usaha mewujudkan komunitas yang unggul sebagaimana pernyataan Fazlur Rahman merupakan usaha yang perlu dibangun dan dibina secara berkesinambungan. Usaha dakwah Nur yang dipandu teks Risale-i Nur merupakan bentuk kongkrit upaya untuk mencapai masyarakat yang ideal tersebut, yang didasarkan pada kepribadian kolektif maknawi (al-shakhs al-mánawi). Ketika kepribadian kolektif dapat terbangun maka akan muncul sikap dan sifat mementingkan orang lain, bahkan ia dapat meleburkan dirinya pada diri orang lain (Al-fana' fi al-ikhwa>n). Bediuzzaman Said Nursi menyatakan:

Ada istilah yang beredar di antara para Sufi, yaitu fana atau lebur dalam diri Shaikh serta lebur dalam diri Rasul. Hanya saja aku bukanlah seorang Sufi. Lebur dalam persaudaraan (Alfana' fi al-ikhwa>n) merupakan prinsip indah yang sangat sesuai dengan perjalanan kita. Dengan kata lain, setiap orang harus meleburkan diri pada yang lain. Yakni, ia harus melupakan perasaan nafsunya dan hidup bersama kemuliaan saudara-saudaranya. Sebab, landasan konsep kita adalah ukhuwah (persaudaraan) di jalan Allah. Hubungan yang mengikat kita adalah persaudaraan yang hakiki...Tentu saja dasar yang paling utama dari persahabatan itu adalah adanya keikhlasan yang tulus. ${ }^{42}$

Menurut Nursi, tersebarnya akhlak tercela karena bersumber dari sikap meninggalkan ajaran agama (sharíat). "Selama kiamat yang dijanjikan kepada manusia belum tiba, maka siapapun mengharapkan rahmat dari Zat yang Maha Pengasih dan Penyayang. Hal tersebut dimaksudkan agar berbagai hakikat al-Qur'an menjadi media yang bisa menyelamatkan umat manusia dari kejatuhan ke tingkat yang paling rendah, serta menegakkan kedamaian yang bersifat universal dan komprehensif."43

Nursi mengajak umat untuk memedomani al-Qur'an hingga kehidupan yang penuh makna dapat tercapai. Nursi membimbing murid-murid Nur agar organisasi dakwah yang penuh berkah tersebut sembilan puluh sembilan persen bukan diarahkan kepada politik. Akan tetapi berupa perbaikan akhlak, sikap istiqamah, serta berbagai sifat mulia lainnya. Sebab, sejumlah perkumpulan yang mengarah kepadannya bisa dikatakan langka padahal urgensinya sangat jelas. Hanya satu persen dari tujuannya yang terkait dengan politik; yaitu membimbing para politisi. Kemudian senjata mereka berupa argumen yang kuat dan meyakinkan. Serta manhaj mereka adalah cinta kasih dan menumbuhkan rasa cinta yang tertanam dalam benih persaudaraan yang terdapat di antara kaum mukmin agar kelak menjadi pohon Tuba penuh berkah. 44

Nursi mengiginkan agar dakwah Nur bersih dari intrik politik, baik itu yang berasal dari dalam gerakan dakwah Nur, maupun dari luar. Keinginannya tersebut tidak lain karena Ingin menjadikan agama sebagai pembimbing bukan pendompleng atau penjilat guna kepentingan sesaat. Dalam dakwah Nur tidak dikenal jenjang karir organisasi. Hal tersebut dimaksudkan agar tidak terjadi persaingan "kursi" yang dapat menyebabkan perpecahan dan kebencian.

Totalitas dakwah diperlukan dalam pelaksanaan amar makruf nahi munkar, sebagaimana masyarakat yang dibangun Nabi Muhammad Saw. M. Yunan mengungkapkan bahwa sejarah 
mencatat masyarakat Madinah pimpinan Rasulullah itu adalah masyarakat plural, multietnik, bahkan multi agama. Tradisi masyarakat egaliter dan partisipatif tersebutlah yang dibangun oleh Nabi di kota Madinah. Nabi sendiri turun tangan dan tampil di tengah masyarakat dengan mengembangkan keberanian untuk memunculkan pendapat banding terhadap kebijakankebijakan Nabi yang bukan berasal dari wahyu. Bila kebijakan itu berasal dari wahyu yang beliau terima dari Allah, mereka berkata, "sami'na> wa at\}a'na>" (kami dengar dan kami patuhi). Tetapi, bila kebajikan itu berasal dari pemikiran Nabi sendiri, mereka tanpa sungkan-sungkan, mengkritik pendapat tersebut bila tidak sesuai dengan pertimbangan akal sehat, dan Nabi sendiri tanpa beban apapun, menerima pendapat banding masyarakat itu, dan kemudian menjadikannya sebagai kebijakan baru. 45

Keberhasilan Nabi dalam membangun masyarakat Madinah didasarkan pada kebersamaan, persatuan serta saling menghormati satu dengan lainnya. Totalitas dakwah Nabi tercermin pula dalam upaya Nursi dalam merespon perkembangan masyarakat Turki yang saat itu berada dalam masa "transisi," politik yang berdampak pada "krisis" agama. Nursi terus mengobarkan semangat bahwa agama harus dipegang erat. Ia mengingatkan para penulis dan penceramah yang berdakwah lewat koran bahwa mereka harus bersikap rendah hati serta bisa melihat kekurangan yang ada. Mereka tidak boleh menyimpang dan menulis sesuatu yang bertentangan dengan syiar Islam. Dari mana mereka mendapat ijin dan dengan hak apa memperlihatkan kekurangan agama, bahkan propaganda sesat yang merugikan agama dan umat. Siapapun tidak boleh berbuat zalim kepada orang lain, apalagi terhadap saudaranya. 46

Lebih lanjut, pentingnya peranan akhlak dalam mewujudkan umat terbaik dalam menyelamatkan kehidupan dan lingkungan masyarakat dinyatakan M. Yunan Yusuf: Akhlak dan moral itu pada hakikatnya adalah kondisi jiwa yang menggerakkan seseorang untuk meelakukan perbuatan. Perbuatan tersebut akan lahir dalam bentuk kebajikan bila digerakkan oleh akhlak dan moral terpuji. Sebaliknya akan lahir perbuatan tercela bila seorang berbuat tanpa mempertimbangkan akhlak dan moralnya. Profil panutan untuk akhlak dan moral itu, tak lain dan tak bukan, adalah dia yang menjadi penghulu para Nabi dan Rasul, dan juga sebagai penutup para Nabi dan Rasul, itulah dia Nabi Muhammad Saw. Yakni seorang manusia pilihan yang menyandang gelar khuluqun azim. Itulah sebabnya beliau oleh Al-Qur'an dinyatakan sebagai uswah hasanah (teladan yang baik). 47

Senada dengan pernyataan Yunan Yusuf, Ali A. Allawi menyatakan bahwa teks al-Qur'an tak pernah berhenti memperingatkan dan mengingatkan manusia bahwa ketundukannya pada perintah-perintah Tuhan harus menjadi dasar etika kehidupan dan perilaku yang permanen, baik etika pribadi sekaligus dasar bagi organisasi publik. Ini adalah titik awal dari semua pengejawantahan Islam yang otoritatif dan telah bertahan mengarungi perubahan-perubahan ruang dan waktu. 48

Akhlak atau etika ${ }^{49}$ merupakan nilai-nilai yang hendaknya menyatu dalam pribadi seorang Muslim yang akan tergambar dan tercermin dalam perilaku moralnya. Apabila ia memiliki akhlak yang baik, maka akan tercermin dalam perilakunya. Komunitarianisme memandang bahwa moral yang dibuat dan disepakati oleh sebuah komunitas memiliki kekuatan hukum yang tertinggi berbanding aturan pemerintah. ${ }^{\circ}$ Jika akhlak menjadi panduan masyarakat maka perwujudan umat terbaik diharapkan dapat pula terwujud. 
Tentulah sumber akhlak tersebut bersumber dari nilai-nilai ajaran agama (Islam), sebagaimana penyataan Quraish Shihab dalam berbagai kesempatan. Interaksi dalam pergaulan saat tinggal di dershane membuat kesan yang positif bagi para Tullab al-Nur. Saling bahu membahu, saling menghormati, berempati, dan kebersamaan dapat mereka rasakan bersama.

\section{Simpulan}

Setelah membahas kajian pemikiran dakwah Said Nursi dan gerakan dakwahnya, maka gerakan tersebut menjadikan teks Risale-i Nur sebagai acuan dan panduan dakwahnya. Semakin patuh pada nilai-nilai kebajikan yang terkandung dalam teks panduan gerakan, maka semakin baik gerakan tersebut dalam membangun komunitas. Adapun kesimpulan rinciannya sebagai berikut: 1) Konsep Murasalah sebagai bentuk Tabligh (Information) yang menekankan pentingya informasi sebagai pesan dakwah dimaknai gerakan ini sebagai upaya menyebarkan dan menyosialisasikan Risale-i Nur ke berbagai lapisan masyarakat. Mura >salah dilakukan Said Nursi dalam usaha pemahaman Risale-i Nur di tengah rezim yang represif saat itu; 2) Konsep Ustadhiyyah al-Qur'an sebagai dasar perubahan (Taghyir), yaitu usaha dakwah agar terjadi perubahan ke arah yang positif setelah menerima informasi berdasarkan spirit Al-Qur'an dan Sunnah. Siapapun yang mendapat informasi dan menelaah Risale-i Nur, khususnya para Murid Nur (Tullab al-Nur) diharapkan dapat berubah dan bertransformasi diri. Tullab al-Nur yang tinggal di dershane pusat di Ciputat

dan dershane-dershane lainnya berusaha menerapkan etika al-Qur'an sebagaimana yang dipesankan dalam tafsir Risale-i Nur dan membentuk pribadi yang mandiri, tekun dalam beribadah, kompak dalam kebersamaan, dan lain-lain; 3) al-Shahs al-Ma'nawi sebagai bentuk Takwin al-Ummah dan al-Amr bi al-Ma'ruf wa al-Nahy 'an al-Munkar (Development), yaitu usaha dakwah Said Nursi dalam membangun komunitas unggul yang berkemajuan dengan upaya transformasi teks Risale-i Nur ke konteks (realitas sosial). Pembangunan yang hendak dicapai dalam dakwah Nur adalah kesadaran umat atas perintah Allah melalui Rasulnya. Dalam mengupayakan Takwin al-Ummah, rutinitas kajian Risale-i Nur diadakan setiap hari bagi mereka yang tinggal di dershane; 4) Konsep Al-fana' fi al-ikhwan dalam mewujudkan khairiyyah alummah/ masyarakat madani/ Civil Society/ Akhlaq (Ethics). Dalam konteks tersebut Said Nursi mengajak umat untuk memedomani sumber ajaran al-Qur'an, Hadith, termasuk tafsirnya Risale- $i$ Nur hingga kehidupan yang penuh makna dapat tercapai, dalam upaya membentuk pribadi yang berakhlak mulia.

\section{Catatan Kaki}

${ }^{1}$ M. Dawam Rahardjo, "Gerakan Islam Kultural Paramadina, Fundamentalisme Agama dan Masa Depan Keislaman dan Keindonesiaan, Titik Temu Jurnal Dialog Peradaban,” Vol. 7, No. 2, Januari-Juni $2015,27$.

${ }^{2}$ M. Dawam Rahardjo, "Gerakan Islam Kultural Paramadina, Fundamentalisme Agama dan Masa Depan Keislaman dan Keindonesiaan," 27.

3Penulis biografi Said Nursi yang cukup otoritatif adalah Şükran Vahide dalam karyanya Islam in Modern Turkey, An Intellectual Biography of Bediuzzaman Said Nursi (Albani: State University of New York Press, 2005), yang sudah diterjemahkan ke dalam bahasa Indonesia oleh Sugeng Haryanto dan Sukono dalam Biografi Intelektual Bediuzzaman Said Nursi, Transformasi Dinasti Usmani Menjadi Republik Turki (Jakarta: Anatolia Prenada Media Group, 2007). Selain Vahide penulis lainnya adalah Ibrahim M. Abu Rabi' (Ed), dalam Islam at the Crossroads: On the Life and 
Thought of Bediuzzaman Said Nursi (New York: SUNY Press, 2003). Penulis lainnya adalah Colin Turner dan Hasan Horkuc, Said Nursi (London: I.B. Tauris \& Oxford University Press, 2009). lihat Juga, Ihsan Qasim Al-Salihi, Nazrah 'Ammah 'An Hayat Badi' al-Zaman Sa'id Al-Nursi. Cairo: Sözler Publications, 2010. Bisa dilihat pula Andrew Rippin (Ed.), The Islamic World (London: Routledge, 2010), cet. II.

4M. Sait Özervarli, "The Reconstruction of Islamic Social Thought in the Modern Period: Nursi's Approach to Religious Discourse in a Changing Society,” Asian Journal of Social Science, (Leiden: BRILL, 2010), Vol. 38, No. 4, 534.

5Lihat Şükran Vahide, Islam in Modern Turkey, An Intellectual Biography of Bediuzzaman Said Nursi.

${ }^{6}$ Zeki Saritoprak dan Griffith, "Fethullah Gülen and the "People of the Book"; A Voice from Turkey for Interfaith Dialogue", http://www.fethullahGülen.org/press-room/islam-in-contemporary turkey/2012-fethullah-Gülen-and-thepeople-of-the-book-a-voice-from turkey-for-interfaith-dialogue.html, diunduh 21 Januari 2013.

7Said Nursi, Ta'liqat' 'ala Burhan al-Galanbawi fi al-Manfiq (Istanbul: Sözler Yayınevi, 1993), 92.

${ }^{8}$ Sistem pendidikan yang dimaksud adalah memadukan unsur dan konsep tradisional, modern (Barat) dan spiritual.

Dimulai 1908, Nursi membuat petisi berupa usulan reformasi pendidikan yang menekankan tiga aspek pendidikan yaitu: sekolah madrasah (medrese), sekolah sekuler baru (mekteb), dan model lembaga-lembaga sufi beserta disiplin ilmunya (tekke). Integrasi ketiga sistem inilah yang inggin Nursi wujudkan dalam kurikulum universitas yang ia gagas. Batu pertama Universitas ini diletakkan 1914, sayang tidak lama kemudian pecah perang dunia I melawan Rusia. Lihat Şükran Vahide, Islam in Modern Turkey.

${ }_{9}^{9}$ Risalah al-Nur ditulis hingga tahun 1950 yang jumlahnya mencapai 130 risalah. Semua risalah tersebut dikumpulkan dengan judul Kulliyat Rasa'il al-Nur, yang memiliki empat seri utama, yaitu al-Kalimat, al-Maktubat, al-Lama'at, dan al-Shu'a'at. Ustad Nursi sendiri yang mengawasi sehingga semuannya selesai tercetak.

${ }^{10}$ Bediuzzaman Said Nursi, Kulliyyat rasa’̉l al-Nur, al-Matubat, terj. dan penyunting Ihsan Qasim al-Salihi (Al-Qa>hirah: Dar Suzlar Linnashr, 2013), 477 .

${ }^{11}$ Gerakan dakwah Nur disebut pula sebagai gerakan yang berorientasi kepada teks (a text-oriented movement/ faithbased text movements), karena diantara usaha dakwah gerakan ini adalah usahanya menerjemahkan dan mencetak karya Nursi ke berbagai bahasa. Lihat Metin Karabaşoğlu, "Text and Community: An Analysis of the Risale-i Nur Movement”, dalam Ibrahim M. Abu Rabi' (Ed), Islam at the Crossroads: On the Life and Thoudht of Bediuzzaman Said Nursi, (Albani: SUNY Press, 2003), 286-287. lihat pula Colin Turner dan Hasan Horkuc, Said Nursi (London: I.B. Tauris \& Oxford University Press, 2009), 90.

${ }^{12}$ Konsep komunitas yang menekankan aspek kepentingan kelompok berbanding individu, hingga melahirkan teori komunitarian (communitarian) pada tahun 1980 digunakan oleh kelompok Marxist untuk mengkritik teori politik liberal. Kelompok komunitarian meyakini bahwa liberalisme menyebabkan lahirnya sifat individual, tidak perduli dengan orang lain dalam sebuah kelompok. Lihat Donald M. Borchert (Ed. In Chief), Encyclopedia of Philosophy, (New York: Thomson Gale, 2006), 368. Dalam perkembangannya, communitarianisme menjadi salah satu tipologi dalam teori normatif hubungan internasional (International relations). Tehranian mulai dari tipologi realism, liberalism, Marxism, communitarianism dan postmodern, lihat Majid Tehranian, Global Communication and World Politics, Domination, Development, and Discourse (New York: Lynne Rienner Publisher, 1999), 30-38.

${ }^{13}$ Karya Ferdinand Tönnies yang memperkenalkan bentuk-bentuk masyarakat adalah Community and society, atau dalam bahasa asli Jermannya Gemeinschaft und Gesellschaft. Karya dalam bahasa Inggris diterjemahkan oleh Charles P. Loomis, (East Lansing, Mich: The Michigan State University Press, 1957), 223-233, kemudian diterbitkan ulang yang dieditori oleh Amitai Etzioni dan Eva Etzioni-Halevy dalam buku yang berjudul Social change, Sources, Patterns and Consequences (USA: Basic Book, 1973), Ed. II., 54-62. Gemeinschaft juga identik dengan paguyuban atau ikatan asosiatif berdasarkan solidaritas dan Gesellschaft cenderung identik dengan patembayan atau ikatan asosiatif berdasarkan perjanjian atau kontrak, lihat Emanuel Adler, Communitarian International Relations, The epistemic foundations of International Relations (New York: Routledge, 2005), 6-7.

${ }^{14}$ lihat Amitai Etzioni dan Eva Etzioni-Halevy, Social Change, Sources, Patterns and Consequences (USA: Basic Book, 1973), Ed. II., 61. lihat pula Soerjono Soekanto, Sosiologi Suatu Pengantar (Jakarta: Rajawali Press, 1999), Cet. XXVII, 448. lihat pula Kamanto Sunarto, Pengantar Sosiologi, (Jakarta: Lembaga Penerbit Fakultas Ekonomi Universitas Indonesia, 2004), 133. lihat pula David Jary dan Julia Jary, Collins Dictionary of Sociology (Great Britain: Harper Collins Publisher, 1991), 98.

${ }_{15}^{15}$ Abdulaziz Sachedina menyebutkan bahwa Islam memiliki kelengkapan secara sosial dan agama ideal yang dapat menginspirasi bentuk-bentuk masyarakat pluralistik, institusi demokrasi dalam percaturan global sebagai komunitas Muslim yang terbaik di abad ke-21 ini. Sachedina mengajak agar umat Muslim dapat merestorasi sejarah awal Islam dalam kehidupan modern. Usaha Nursi atas proposal konsep pendidikannya tidak lain merupakan upaya restorasi komunitas (Ummah) agar tidak terjebak pada tradisi dan merespon modernitas. Lihat Abdulaziz Sachedina, The Islamic Roots of Democratic Pluralism (New York: Oxford University Press, 2001), 139.

${ }^{16}$ Lihat Thomas Riggs (Ed.), Worldmark Encyclopedia of Religious Practices (New York: Thomson Gale, 2006), Vol. III, 482.

${ }^{17}$ Lihat Ibn Khaldūn, The Muqaddimah, An Introduction to History, Trans. Franz Rosenthal (from Arabic), (United Kingdom: Princeton University Press, 1989), 127. lihat pula Hamid Mowlana, Global Communication in Transition, The End of Diversity? (California: Sage Publications, 1996), 116. lihat pula A. Cf. Cheddadi, "Le Pouvoir Selon Ibn Khadūn", 
Annales E.S.P. (Paris), 1980, 3-4, dalam Mohammed Arkoun, terj. Rahayu S. Hidayat, Nalar Islami dan Nalar Modern: Berbagai Tantangan dan Jalan Baru (Jakarta: INIS, 1994).

${ }^{18}$ Agama (Islam) yang inklusif sebagai gambaran masyarakat Islam di Jawa pasca 1965 yang Bambang Pranowo gambarkan dan analogikan sebagai kue lapis yang terdiri dari beberapa lapisan warna-warni. Betapapun dominanya warna tertentu, tapi ia bukanlah keseluruhan dari kue lapis tersebut. Sebaliknya, jika ada warna lain yang dianggap dominan, merah misalnya, ia merupakan bagian tidak terpisahkan dari kue lapis yang satu. Karena itu, tegas Bambang, jangan sekali-kali memandang lapisan tersebut sebagai bukan "kue lapis" Islam. Lihat H.M. Bambang Pranowo, "Runtuhnya Dikotomi Santri-Abangan, Refleksi atas Perkembangan Islam Islam di Jawa Pasca 1965," Pidato pengukuhan Guru Besar dalam Ilmu Sosiologi Agama Pada Fakultas Ushuluddin IAIN Syarif Hidayatullah Jakarta, 2001, 34 .

${ }^{19}$ Lihat Andi Faisal Bakti dan Venny Eka Meidasari, ”Trensetter Komunikasi di Era Digital: Tantangan dan Peluang Pendidikan Komunikasi dan Penyiaran Islam”, Jurnal Komunikasi Islam, Vol. 02, No. 01, Juni 2012, 4.

${ }^{20}$ Lihat Andi Faisal Bakti, "Relefansi Pemikiran Nurcholish Madjid untuk Pembangunan Bangsa," Titik Temu Jurnal Dialog Peradaban, Vol. 6, No. 1, Juli-Desember 2013, 39.

${ }^{21}$ Lihat Isma'il R. Al-Faruqi dan Lois Lamya Al-Faruqi, Atlas Budaya Islam, Menjelajah Khazanah Peradaban Gemilang, (Bandung: Mizan, 1998), 217. Diterjemahkan dari The Cultural Atlas of Islam, (New York: Macmillan Publishing Company, 1986).

${ }^{22}$ Menurut Bakti, dalam ilmu dakwah dan komunikasi dikenal empat level kesuksesan dalam berkomunikasi, yang pertama yaitu level menyampaikan (tabli>gh) sebuah pesan kepada orang lain, dalam hal ini targetnya adalah pemahaman dan pemaknaan. Lihat Andi Faisal Bakti, "Konstruksi Dakwah Islam Universal Melalui Haji," dalam Dinamika dan Perspektif Haji Indonesia (Jakarta: Kementerian Agama RI Direktorat Jenderal Penyelenggaraan Haji dan Umrah, 2010), 127. lihat pula Andi Faisal Bakti, "The Contribution of Dakwah to Communication Studies: Risale-i Nur Collection Perspective", International Bediuzzaman Symposium, Knowledge, Faith, Morality and the Future oh Humanity (Istanbul: The Istanbul Foundation for Science and Culture, 2010), 195-213.

${ }^{23}$ Lihat Ihsan Qasim al-Salihi pengantar penerjemah dalam Bediuzzaman Said Nursi, Kulliyyat Rasäl al-Nur, al-Malahiq Fifiqh Daiwah al-Nur, terj. dan penyunting Ihsan Qa>sim al-Salihi (Al-Qahirah: Dar Suzlar Linnashr, 2013$), 8$.

${ }^{24}$ Adib Ibrahim Dabbag, catatan pendahuluan dari Risalah khusus yang dikumpulkan oleh Tullab al-Nur Zubair Kondoz Alab yang kemudian diberi judul Khidmah Rahbari yang kemudian diterjemahkan ke Bahasa Arab oleh Ihsan Qasim al-Salihi dengan judul, Kulliyat Rasail al-Nur, Murshid Ahl al-Qur'an Ila Haqa'iq al-Iman (Al-Qahirah: Dar Suzlar linnashr, 2004), 7. Saat penerjemahan ke bahasa Arab inilah, penerjemah Ihsan Qa>sim meminta Adib Ibrahim Dabbag yang berkebangsaan Irak untuk memberi sambutan. Buku tersebut juga telah diterjemahkan ke dalam bahasa Indonesia, dengan judul Murshid Ahlu al-Qur'an Ila Haqaiq al-Iman, terj. Hasanuddin Alimuddin, Mahkamah Mahdin \& Syamsu Alam Darwis, (Cairo: Sözler Publications, 2008).

25Bediuzzaman Said Nursi, Kulliyyat Rasa’il al-Nur, al-Mathnawi al-'Arabi al-Nuri. Terj. dan Penyunting Ihsan Qasim al-Shalihi (Al-Qahirah: Dar Suzlar linnashr, 2013), 234.

${ }^{26}$ Ali Shari'ati, Islam Mazhab Pemikiran dan Aksi, terj. M.S. Nasrullah dan Afif Muhammad (Bandung: Mizan, 1995), 107.

${ }^{27}$ Lihat Bediuzzaman Said Nursi, From the Risale-i Nur Collection, The Flashes, Terj. Şükran Vahide (Istanbul: Sözler Nesriyat, 2013), 179-180. Lihat pula Andi Faisal Bakti, The Contribution of Dakwah to Communication Studies: Risale-i Nur Collection Perspective, International Bediuzzaman Symposium, Knowledge, Faith, Morality and the Future oh Humanity (Istanbul: The Istambul Foundation for Science and Culture, 2010), 199-200.

${ }^{28}$ Lihat Andi Faisal Bakti, The Contribution of Dakwah to Communication Studies: Risale-i Nur Collection Perspective, International Bediuzzaman Symposium, 200.

${ }^{29}$ Said Nursi, Murshid Ahl al-Qur'an Ila Haqa’iq al-Iman, 80.

${ }^{30}$ Lihat Andi Faisal Bakti, The Contribution of Dakwah to Communication Studies: Risale-i Nur Collection Perspective, International Bediuzzaman Symposium, 204.

${ }^{31}$ Ayat yang seringkali dirujuk ketika berbicara amar makruf nahi mungkar adalah surat Ali 'Imran ayat 104.

${ }^{32}$ Mowlana menegaskan amar makruf nahi munkar menuntut prinsip adanya tanggung jawab individual dan

kelompok dalam menyiapkan generasi penerus untuk menerima ajaran-ajaran Islam dan mengambil manfaat darinya. Lihat Hamid Mowlana, Global Communication in Transition, The End of Diversity? (California: Sage Publications, 1996), 121-122.

33Bediuzzaman Said Nursi, Kulliyat Rasail al-Nur, Murshid Ahl al-Qur'an Ila Haqa’iq al-Iman, terj. Ihsan Qasim alSalihi (Al-Qahirah: Dar Suzlar linnashr, 2004), 101.

34Hamid Mowlana, Global Communication in Transition, The End of Diversity? (California: Sage Publications, 1996), 121.

35Wawancara dengan Eyup Aluçluer 14 Oktober 2016

${ }^{36}$ Lihat Mulyadi Kartanegara, Etika: The Art of Living dalam Menembus Batas Waktu, Panorama Filsafat Islam (Bandung: Mizan, 2002), 67-84.

37Lihat Bediuzzaman Said Nursi, Kulliyyat Rasa’il al-Nur, S\}aiqal al-Islam au Athar Said al-Qadim, 369-370.

${ }^{38}$ Bediuzzaman Said Nursi, Kulliyyat Rasä̈l al-Nur, Słaiqal al-Islam au Athar Saìd al-Qadim, 370.

39Muhammad Fethullah Gülen, "Taqdim", dalam Kulliyyatrasa’il al-Nur, al-Lama'at, 11.

11.

40Abd. Moqsith Ghazali, Tafsir atas Amar Makruf Nahi Mungkar dalam Islam, Titik-Temu Jurnal Dialog Peradaban, Vol. 7, No. 1, Juli-Desember 2014, 57.

${ }^{41}$ Lihat Fazlur Rahman, Metode dan Alternatif Neomodernisme Islam, terj. Taufik Adnan Amal, (Bandung: Mizan, 1994), 67.

${ }^{42}$ Bediuzzaman Said Nursi, Kulliyyat Rasäl al-Nur, al-Lama'a >t, terj. dan penyunting Ihsan Qasim al-Salihi (Al-Qahirah: Dar Suzlar Linnashr, 2013), 225. 
43Bediuzzaman Said Nursi, Kulliyyat Rasaỉl al-Nur, Słaiqal al-Islam au Athar Said al-Qadim, 474.

44Bediuzzaman Said Nursi, Kulliyyat Rasäll al-Nur, Słaiqal al-Islam au Athar Said al-Qadim, 503.

45M. Yunan Yusuf, Tafsir Al-Qur'an Juz XXVIII Juz Qad Samiallah, Bun-yanun Marshush, Bangunan Kokoh Rapi

(Jakarta: Lentera hati, 2014), 7-8.

${ }^{46}$ Bediuzzaman Said Nursi, Kulliyyat Rasa'il al-Nur, al-Mathnawi al-'Arabi al-Nuri. Terj. dan Penyunting Ihsan Qasim al-Shalihi (Al-Qa>hirah: Dar Suzlar Linnashr, 2013), 186.

47M. Yunan Yusuf, Tafsir Al-Qur’an Juz Tabarak, Khuluqun ‘Azim (Budi Pekerti Agung), 11.

${ }^{48}$ Ali A. Allawi, Krisis Peradaban Islam, Antara Kebangkitan dan Keruntuhan Total, terj. Pilar Muhammad Mochtar (Bandung: Mizan, 2015), 38. Buku tersebut merupakan terjemahan dari The Crisis of Islamic Civilization (London: Yale University Press, 2009).

49Dalam tradisi filsafat "etika" lazim dipahami sebagai suatu teori ilmu pengetahuan yang mendiskusikan mengenai apa yang baik dan apa yang buruk berkenaan dengan perilaku manusia. Persoalan etika muncul ketika moralitas seseorang atau suatu masyarakat mulai ditinjau lagi secara kritis. Sedangkan moralitas berkenaan berkenaan dengan tingkah laku yang kongkrit, sedangkan etika bekerja pada level teori. Lihat Paul W. Tailor, Problems of Moral Philosophy, (California: Deckenson Publishing Compant Inc., 1992), 3.

${ }^{5}$ In essence, moral judgements are best made at the community lever rather than from the higher governing bodies.

Lebih lanjut lihat Karen Christensen and David Levinson, eds., "Communitarianism," Encyclopedia of Community: From the Village to the Virtual World, Vol 1, A-D (Sage Publications, 2003), 224-228. 